\title{
WEB MAPPING USING LOGO ON MAP
}

\author{
Ximing Hou ${ }^{1,2}$ and Hao Shi ${ }^{2}$ \\ ${ }^{1}$ School of Computer Science, College of Engineering and Computer Science, Australian National \\ University, Canberra, Australia \\ ximing.developeregmail.com \\ ${ }^{2}$ School of Engineering and Science, Victoria University, Melbourne, Australia \\ hao.shi@vu.edu. au
}

\begin{abstract}
The newly proposed Logo on Map (LoM) system consists of three modules: picture extraction module (PEM), logo matching module (LMM) and web mapping module (WMM). Since the first two modules were covered in our previous paper, the third module WMM is described here to present a complete LoM system. Current research is focused on geo-location distribution of brands on Google Maps. Pictures taken by ordinary people are extracted using Picture Extraction Module (PEM). The pictures containing relevant logos are obtained via Logo Matching Module (LMM). Brand distributions are overlaid on Google Maps. In this paper, GPS and brands are briefly described, and the implementation of Web Mapping Module (WMM) based on Google Maps API is detailed. Then several experiments are carried out on the selected top brands. Finally the LMM-pictures are mapped on the Google Maps and the geographical distributions of the brands are visualised. Brand uniqueness is discussed and conclusion is drawn that with unique brand names web mapping can visually reflect the real economic activities of a company in the world.
\end{abstract}

\section{KEYWORDS}

Web mining, Flick, Google API, Log, Brand names, Popularity, GPS, Geographical information

\section{INTRODUCTION}

GPS-enabled devices have become much more popular in the very recent years, which have dramatically changed people's travelling behaviours such as walking, cycling and driving[1]. More importantly, it is more convenient for people to record the geo-location information when they take pictures because most smart phones support GPS. With geo-location information, people can easily label things on Google Maps to view their geo-locations.

On the other hand, brand names have significant implications for companies' products and play imperative roles in global commercial activities and can make a substantial impact on the success of a business. A strong brand name gives consumers confidence about the company products and make the business more popular while a weak brand is susceptible to scrutiny by critics, encroachment from competitors and increased pressure from channel partners [1]. The stronger the brand, the more efficient and effective a company becomes, the higher the market shares it has[1].

In order to view the geographical distribution of a brand more intuitively on Internet, it is necessary to display geo-locations of a logo picture on a world map. Currently, there are a few free web mapping services available [2]. For example, Google ${ }^{\circledR}$ Maps [3], Bing® Maps [4] and Yahoo® Map [5] all provide geographical information on web, Google ${ }^{\circledR}$ Maps being the most popular one [2]. It not only provides user friendly GUI but also comes with a reliable API [3] and built-in essential functions which allow developers to create a visual dynamic map and label signs

DOI : 10.5121/ijma.2012.4601 
The International Journal of Multimedia \& Its Applications (IJMA) Vol.4, No.6, December 2012

to a specific locations. Therefore, Google ${ }^{\circledR}$ Maps has been adopted in LoM system as the web mapping server [6] .

\section{DESIGN AND IMPLEMENTATION OF 'LOGO ON MAP'}

\subsection{Architecture of Logo on Map (LoM)}

LoM (Logo on Map) consists of three main modules as shown in Figure 1:

- Textual search, Picture Extraction Module (PEM)

- Visual search, Logo Matching Module (LMM)

- GPS-based Web Mapping Module (WMM)

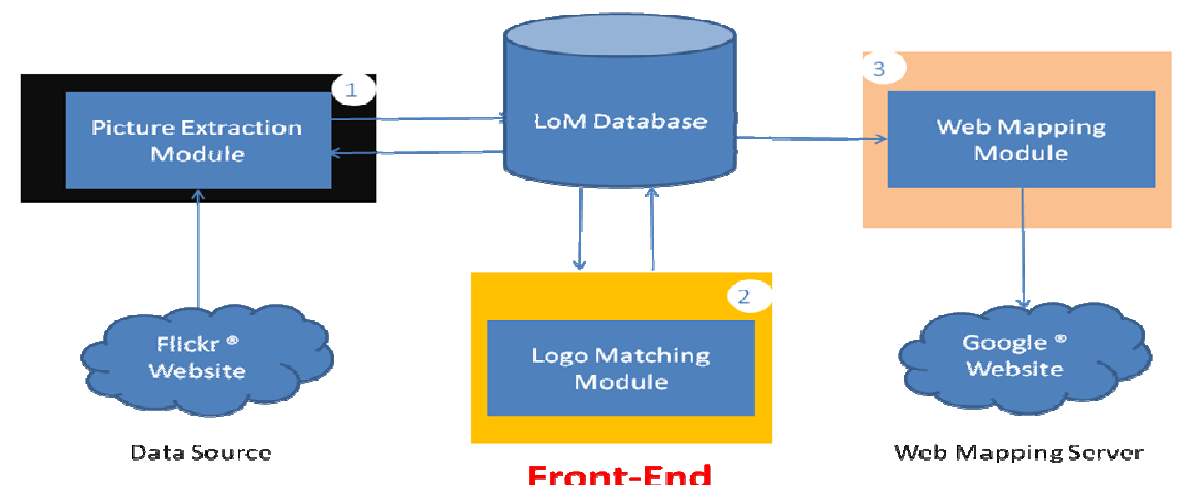

Figure 1. LoM (Logo on Map) architecture [6]

\subsection{Google Maps API}

In order to call and use Google Maps API, it is necessary to load the JavaScript with a registered API key in the page as shown below:

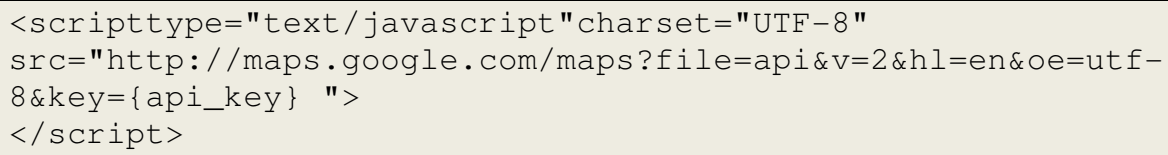

After registration, a pin based on its geo-location information, i.e., longitude and latitude can be mapped on Google Maps based on the following two functions:

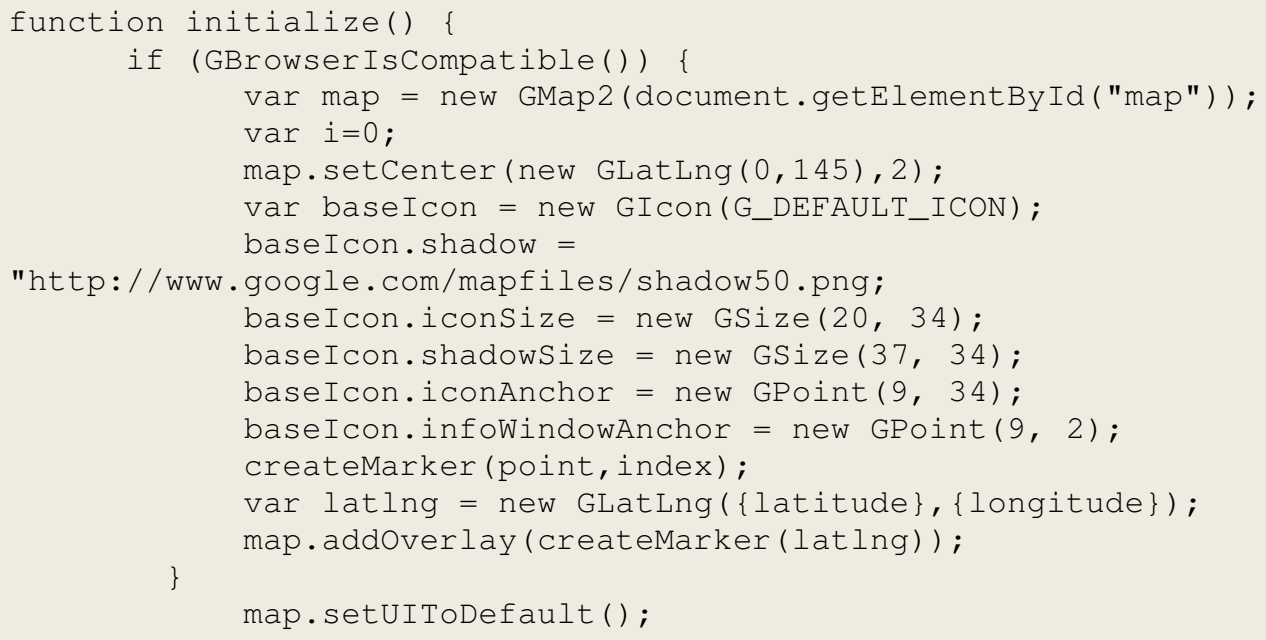


The International Journal of Multimedia \& Its Applications (IJMA) Vol.4, No.6, December 2012

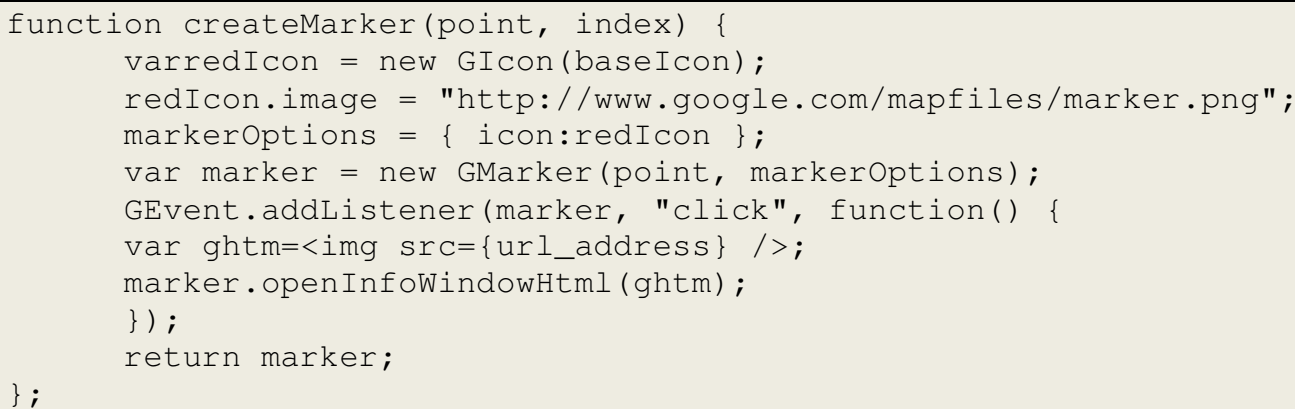

\subsection{Web Mapping Module (WMM)}

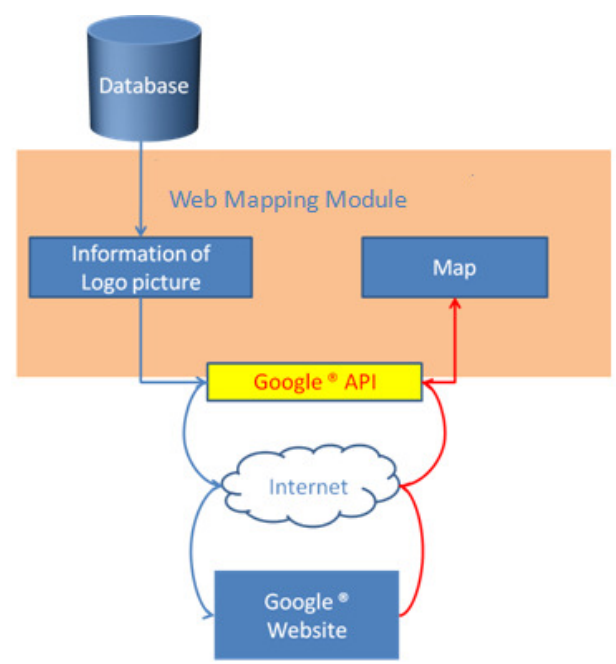

Figure 2.Web Mapping Module (WMM)

There are three steps in LoM System [6]. First, pictures taken by ordinary people are extracted from Flickr website using Picture Extraction Module (PEM). Then picture containing relevant logos are obtained via Logo Matching Module (LMM). Finally implementation of Web Mapping Module (WMM) based on a Google Maps API is executed as illustrated in Figure 2. LMMpictures can be marked based on their geographical locations on Google Maps and their geographical distribution can be visualised. During the initial trial, the same 50-PEM pictures from the previous paper [6] are re-used. The KFC logo is illustrated in Figure 3 and LMMpictures are screened out as shown in Figure 4. The distribution of the LMM-pictures with a $\mathrm{KFC} \circledast \operatorname{logo}$ is obtained and shown in Figure 5.

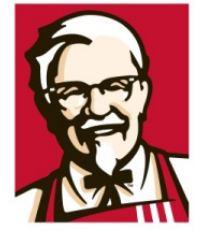

Figure 3 The standard KFC logo [7] 
The International Journal of Multimedia \& Its Applications (IJMA) Vol.4, No.6, December 2012

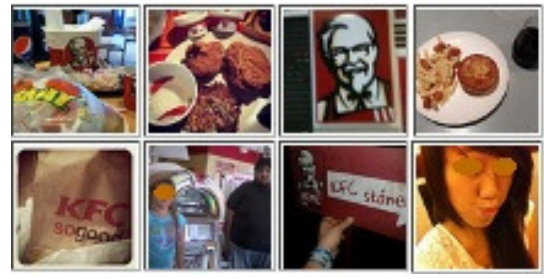

Figure 4. LMM-pictures with KFC® logo [6]

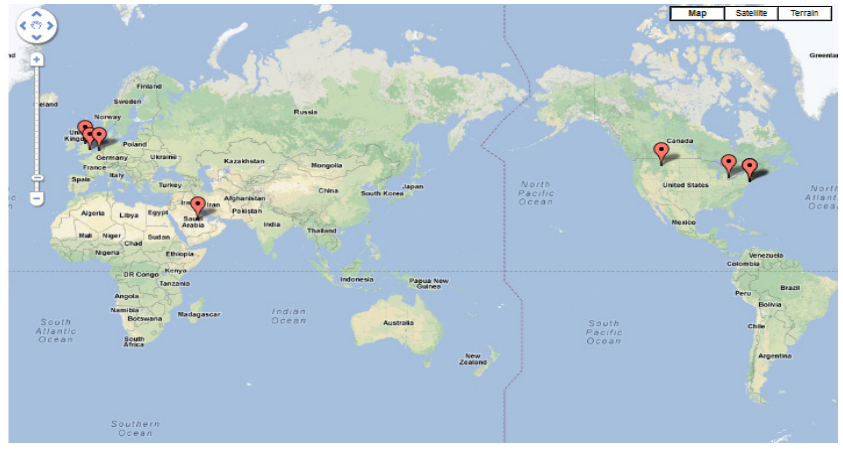

Figure 5.Distribution of KFC® brand around the world*

*Somemarkers are overlapped.

It is clear from Figure 5 that KFC® brand has strong presence in Europe, North America and Eastern Asia where developed and wealthy countries are situated and the emerging economic activities are concentrated.

\section{EXPERIMENTS}

Nowadays, millions of brands have been registered and a good brand name can make a company uniquely different from its competitors and it is also an emotional tug that connects consumers with the company[8]. Therefore, naming and promoting a brand name is one of the most important business activities inside a company. Because of the wide use of the Internet, to obtain a better search result of their name is a way to promote their brand.

In the experiments, three top brands are selected: Starbucks ${ }^{\circledR}[9]$, Alfa Romeo ${ }^{\circledR}[10]$ and KFC ${ }^{\circledR}$ [7] as shown in Figure 6.

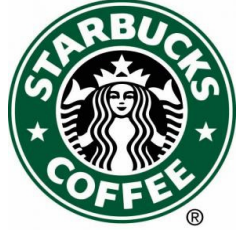

(a) Starbucks ${ }^{\circledR}$

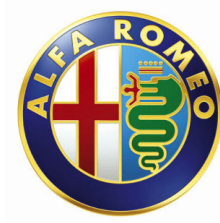

(b) Alfa Romeo®

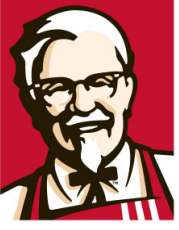

(c) FKC

Figure 6 Three brand logos

\subsection{PEM-pictures and LMM-pictures}

Based on PEM, 50 pictures are downloaded from each brand and the results, i.e. PEM-pictures are shown in Figure 7. After Logo Matching Module (LMM), their LMM-pictures are obtained as shown in Figure 8. 
The International Journal of Multimedia \& Its Applications (IJMA) Vol.4, No.6, December 2012

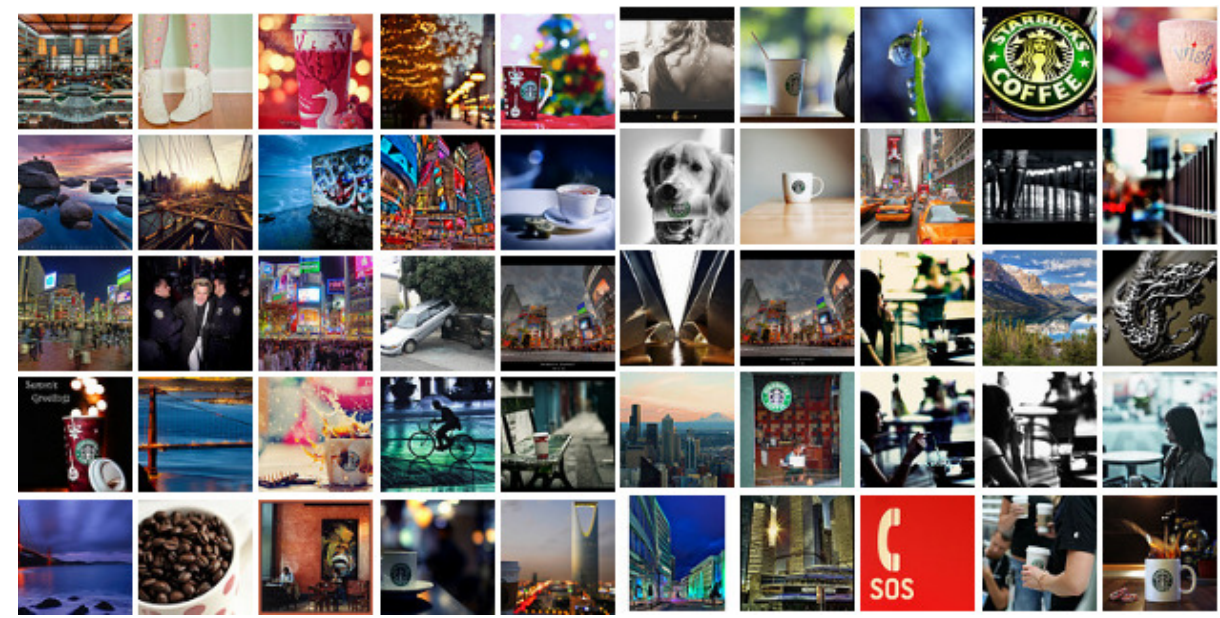

(a) "Starbucks"

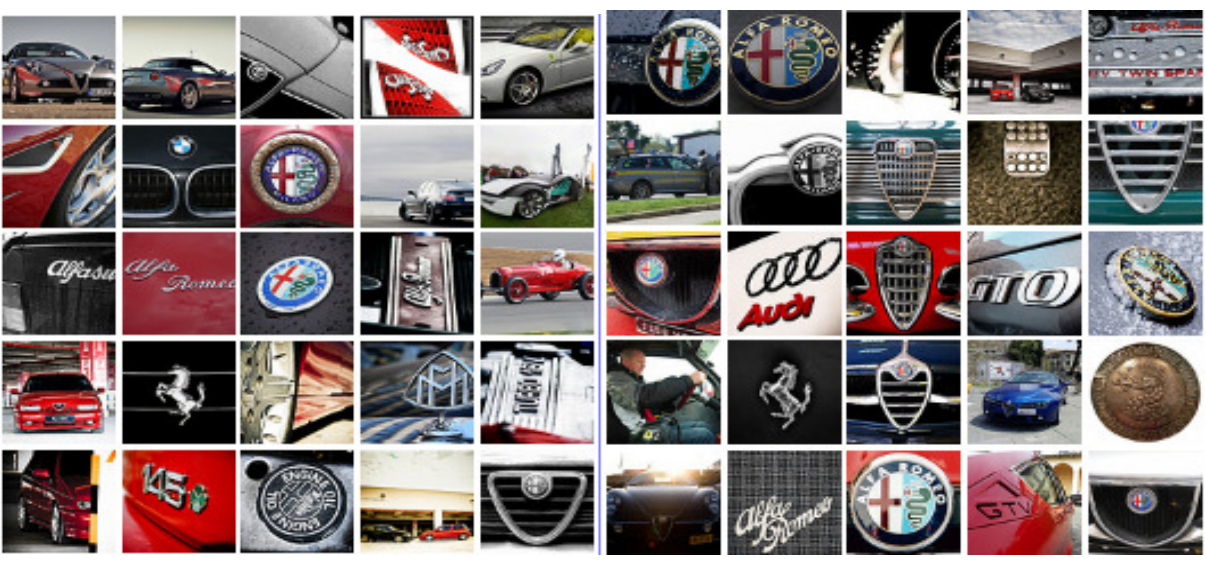

(b) "Alfa Romeo"

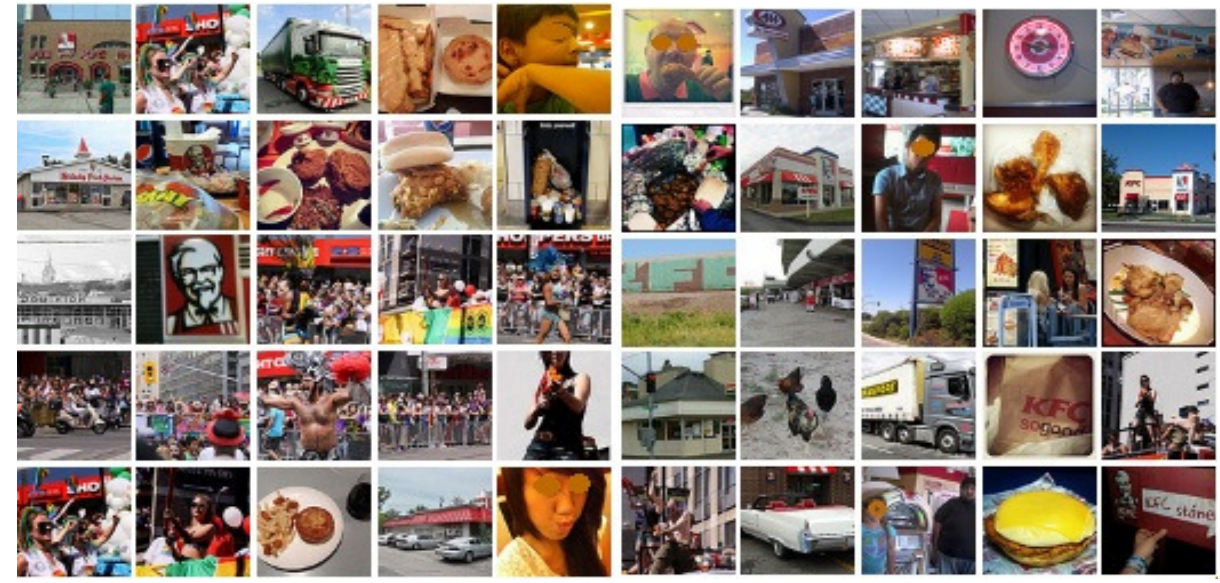

(c) KFC [6]

Figure 7.50 PEM-pictures for each brand downloaded from Flickr® using keywords 
The International Journal of Multimedia \& Its Applications (IJMA) Vol.4, No.6, December 2012

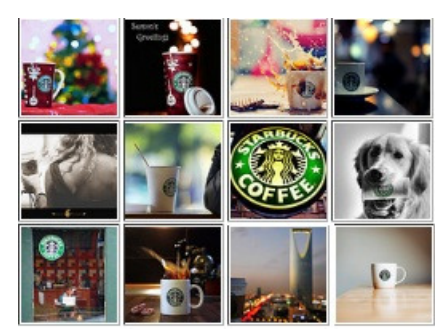

(a) Starbucks

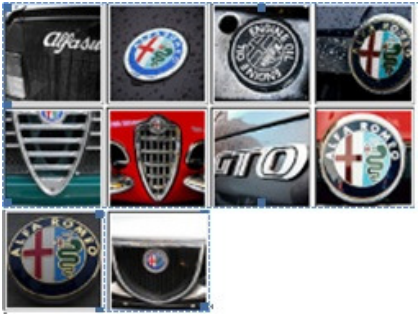

(b) Alfa Romeo

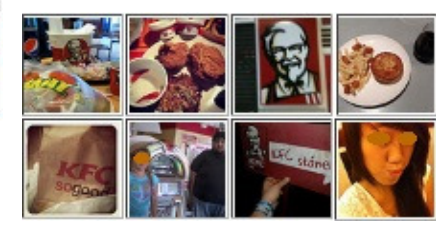

(c) KFC

Figure 8. LMM-pictures obtained from 50 PEM-pictures

\subsection{Statistical Results}

The Recognition Rate for each brand is obtained and listed in Table 1.

Table 1. Recognition Rate

\begin{tabular}{l|c|c}
\hline Brand & Logo Recognized & Percentages (\%) \\
\hline Starbucks ${ }^{\circledR}$ & 12 & 24.0 \\
Alfa Romeo ${ }^{\circledR}$ & 10 & 20.0 \\
KFC & 8 & 16.0 \\
\hline
\end{tabular}

The number of the downloaded pictures is subsequently increased to 100 and 200 PEM-pictures for each brand and their corresponding Recognition Rates are summarised in Table 2.

Table 2.Summary of Recognition Rates

\begin{tabular}{l|rrr|rrr}
\hline Brand & \multicolumn{3}{|c|}{ Logo Recognized } & \multicolumn{3}{c}{ Percentages (\%) } \\
\hline Number of PEM-Pictures & 50 & 100 & 200 & 50 & 100 & 200 \\
\hline Starbucks ${ }^{\circledR}$ & 12 & 21 & 43 & 24.0 & 21.0 & 21.5 \\
Alfa Romeo ${ }^{\circledR}$ & 10 & 22 & 40 & 20.0 & 22.0 & 20.0 \\
KFC ${ }^{\circledR}$ & 8 & 15 & 32 & 16.0 & 15.0 & 16.0 \\
\hline
\end{tabular}

The average Recognition Rates are calculated and listed in Table 3 and illustrated in Figure 9.

Table 3. Average Recognition Rates

\begin{tabular}{l|c}
\hline Brand & Average Percentages (\%) \\
\hline Starbucks ${ }^{\circledR}$ & 21.71 \\
Alfa Romeo ${ }^{\circledR}$ & 20.57 \\
KFC $®$ & 15.71 \\
\hline
\end{tabular}

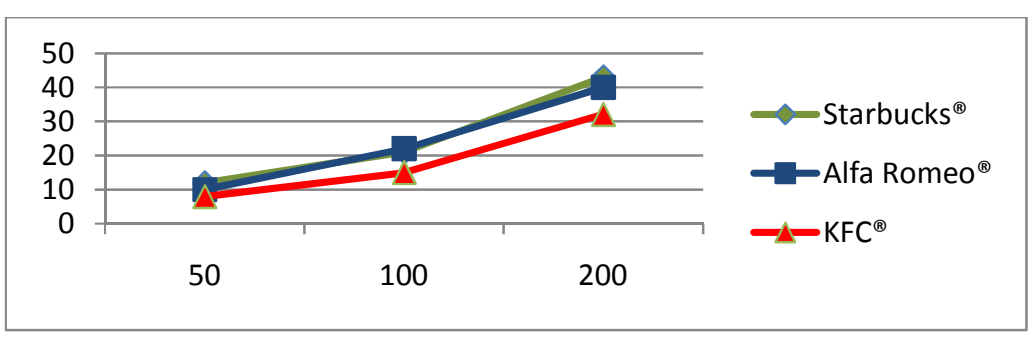

Figure 9. Average Recognition Rates 
The International Journal of Multimedia \& Its Applications (IJMA) Vol.4, No.6, December 2012

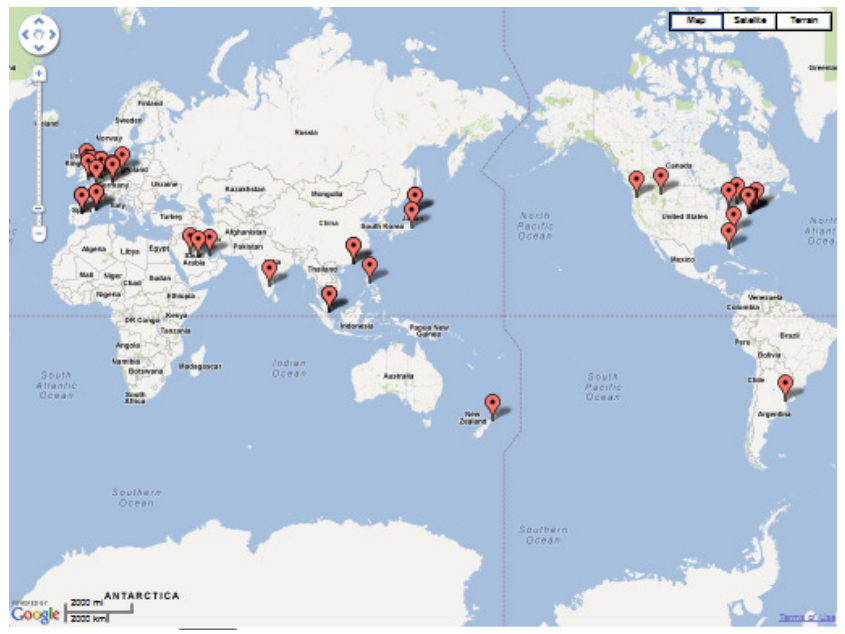

(a) Starbucks®

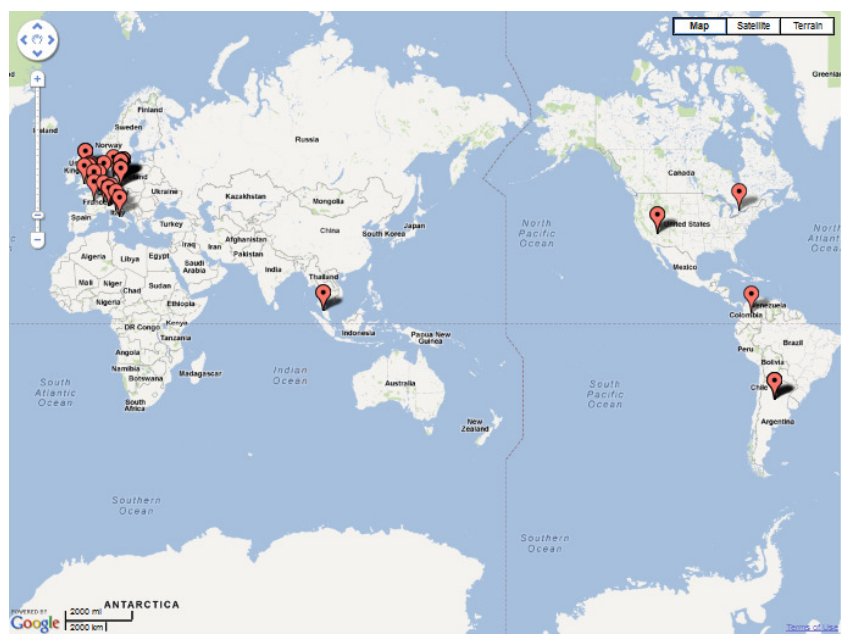

(b) Alfa Romeo®

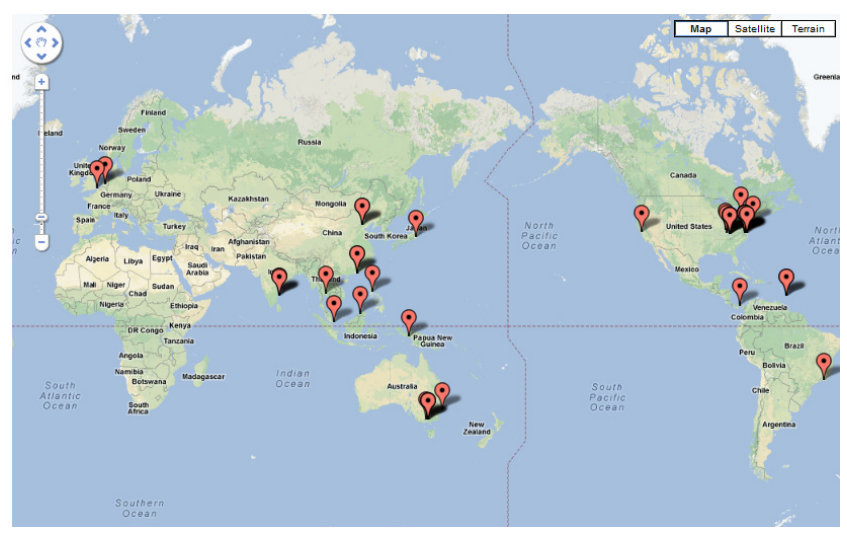

(c) $\mathrm{KFC} 囚$

Figure10 The geographical distributions of each brand* *Some pinpoints are overlapped. 
The International Journal of Multimedia \& Its Applications (IJMA) Vol.4, No.6, December 2012

\subsection{Web Mapping}

Once LMM-pictures are obtained, they can be mapped on Google Maps according to Web Mapping Module (WMM). The geographical distribution of brands of Starbucks $®$, Alfa Romeo® and KFC $®$ from 200 PEM-pictures are illustrated in Figure 10.

It is obvious that the Starbucks $®$ brand mainly concentrated in America and Europe which matches the real situation that the economy and commercial are much more active in these parts of the world. For Alfa Romeo, the pictures mainly concentrate in Europe which indicates that the Alfa Romeo®vehicles are much more popular in Europe rather than other parts of the world. For KFC® which is a world class popular fast food brand, its distribution can be easily observed from the map that it is mainly concentrated in Asia, Australia, Europe and America, where most of the countries have the above average economy status in the world.

\section{DISCUSSIONS}

Starbucks ${ }^{\circledR}$, Alfa Romeo® and KFC® are well-known brands with unique meanings. However, some other brands are also famous but have ambiguous meanings such as Apple® [11] and Shell® [12]. As shown in Figure 11(a), apple can mean the fruit or the Apple® computer while shell can mean a sea shell as well as the global oil company as shown in Figure 11(b).

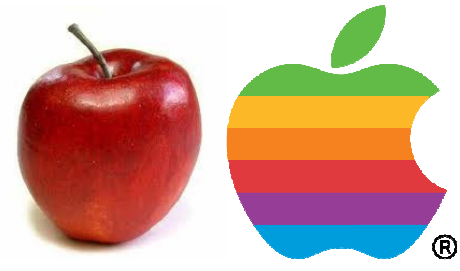

(a) apples

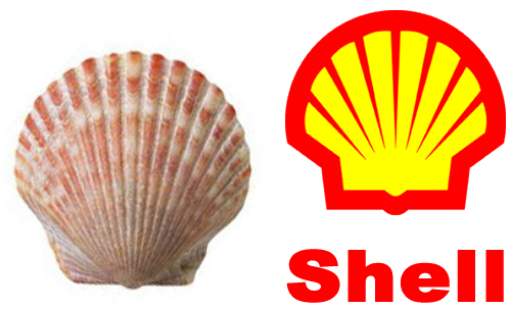

(b) shells

Figure 11. Multiple meanings of brand names

If 50 pictures for Apple $₫$ and Shell® are downloaded from Flickr® website as shown in Figure 12, only one Apple® logo and zero Shell® logo are identified using LoM because most of the pictures are the apple fruits and sea shells, rather than the brand logos. The recognition rates are calculated and listed in Table 3. Even though when the number of download pictures is increased to 100 and 200, the recognition rates remain low as shown in Table 4. 
The International Journal of Multimedia \& Its Applications (IJMA) Vol.4, No.6, December 2012

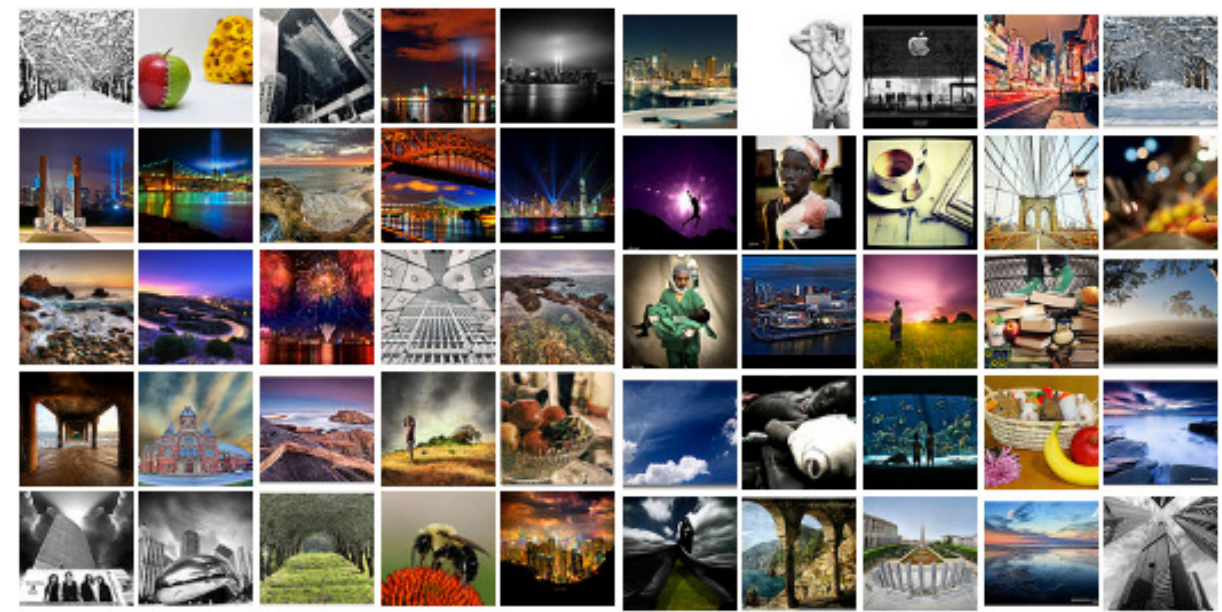

(a) "apple"

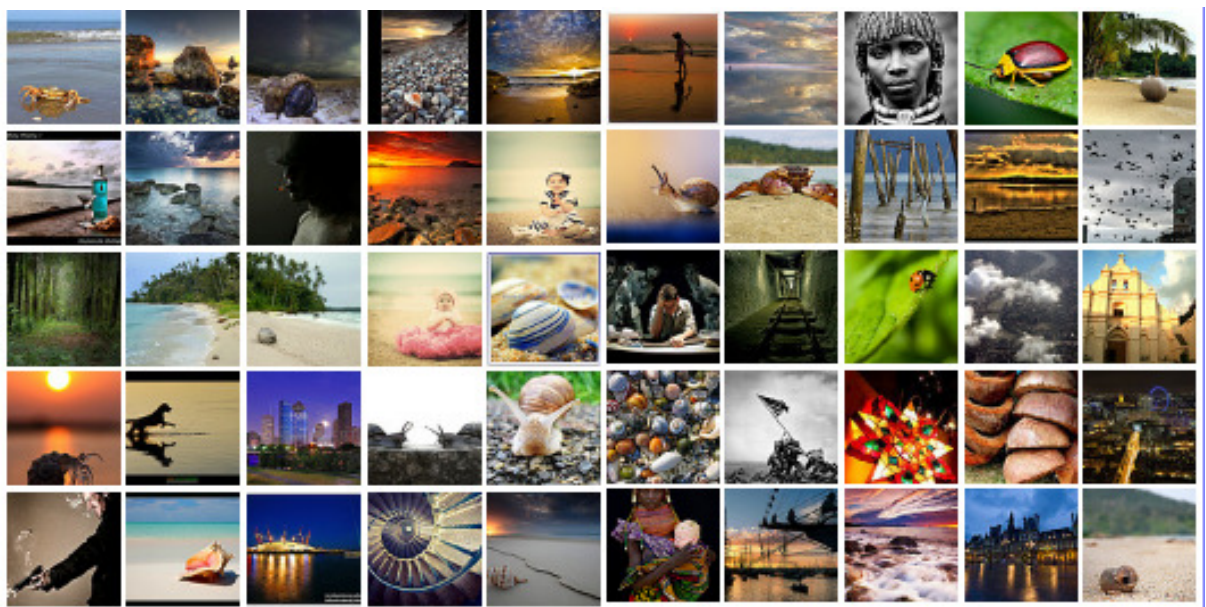

(b) "shell"

Figure 12. 50 PEM-pictures downloaded from Flickr® using keyword "apple" and "shell"

Table 3. Recognition Rate

\begin{tabular}{l|c|c}
\hline Brand & Logo Recognized & Percentages (\%) \\
\hline Apple ${ }^{\circledR}$ & 1 & 2.0 \\
Shell $\circledR$ & 0 & 0.0 \\
\hline
\end{tabular}

Table 4. Summary of Recognition Rates

\begin{tabular}{l|rrr|rrr}
\hline Brand & \multicolumn{3}{|c|}{ Logo Recognized } & \multicolumn{3}{c}{ Percentages (\%) } \\
\hline Number of PEM-Pictures & 50 & 100 & 200 & 50 & 100 & 200 \\
\hline Apple ${ }^{\circledR}$ & 1 & 1 & 4 & 2.0 & 1.0 & 2.0 \\
Shell & 0 & 0 & 0 & 0 & 0 & 0 \\
\hline
\end{tabular}


The International Journal of Multimedia \& Its Applications (IJMA) Vol.4, No.6, December 2012

\section{Conclusions}

As GPS is becoming more widely used in various devices, it is possible to combine GPS with mobile devices using pattern recognition mechanism not only to obtain much cleaner image data and their detail information, but also to obtain their geo-locations in order to obtain a better understanding of their geographical distribution. The newly proposed LoM allows users to effectively label the logos based on their geo-location on Google Maps which can produce the geo-location distribution of a brand around the world. So LoM relies on the pictures taken by ordinary people to identify the real economic activities of a company in the world. According to the experimental results and discussions, if search is done by brand names as keywords, the Starbucks ${ }^{\circledR}$, Alfa Romeo ${ }^{\circledR}$ and the KFC ${ }^{\circledR}$ have relatively high accuracy because their brand names have a unique meaning in people's mind as well as English dictionary. However, Apple ${ }^{\circledR}$ and Shell® have a very low accuracy because their brand names have broad meanings which can represent many objects in people's mind or in a dictionary. They are not a good choice for online search engines. It can be concluded that unique brand name give a company a better online presence and search results. Therefore, to improve opportunities and better search results, a brand should maintain uniqueness and avoid naming brands in plain English at any cost.

\section{REFERENCES}

[1] Lee Yohn, "How Strong is Your Brand? ", 2 February 2009, http://www.brandchannel.com/brand_speak.asp?bs_id=211

[2] Online map services, http://en.wikipedia.org/wiki/List_of_online_map_services

[3] Google Maps APIs, https://developers.google.com/maps/

[4] Bing® Maps, http://www.bing.com/maps/

[5] Yahoo® Maps, http://maps.yahoo.com/

[6] Ximing Hou and Hao Shi, ' Logo Recognition Using Textual and Visual Search', The International Journal of Multimedia \& Its Applications (IJMA) Vol.4, No.5, October 2012, pp. 51-60.

[7] KFC®, http://www.kfc.com

[8] D. Branding Thoughts. "The Name Game - Is it as simple as it looks?" http://edifice.com.sg/blog/category/d-branding-thoughts/

[9] Starbucks®, http://www.starbucks.com/

[10] Alfa Romeo®,http://www.alfaromeo.com

[11] Apple®, http://www.apple.com/

[12] Shell@, http://www.shell.com/ 
The International Journal of Multimedia \& Its Applications (IJMA) Vol.4, No.6, December 2012

\section{Authors}

XimingHou completed his Master of Computing at Australian National University in 2011 and obtained his Bachelor of Computer Science degree at Victoria University in 2008 and Bachelor of Computer Science in Henan University, China in 2006. His research interests include Data Mining, Pattern Recognition and Geographical Information.

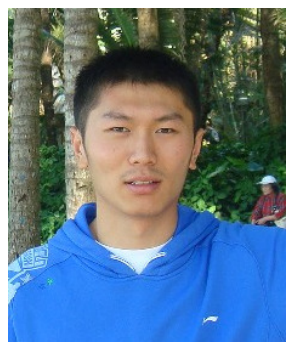

Hao Shi is an Associate Professor in School of Engineering and Science at Victoria University, Australia. She completed her PhD in the area of Computer Engineering at University of Wollongong and obtained her Bachelor of Engineering degree at Shanghai Jiao Tong University, China. She has been actively engaged in R\&D and external consultancy activities. Her research interests include Location-Based Services, Web Services, Computer/Robotics Vision, Visual Communications, Internet and Multimedia Technologies, and Data Mining.

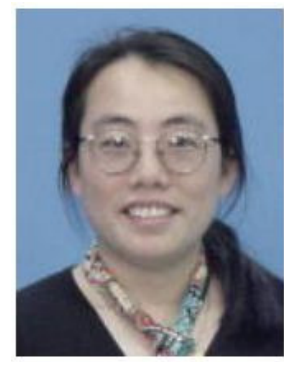

